\title{
SOMBREAMENTO ARBÓREO E ORIENTAÇÃO DE INSTALAÇÕES AVÍCOLAS
}

\section{SULIVAN P. ALVES ${ }^{1}$, EDMUNDO H. V. RODRIGUES ${ }^{2}$}

RESUMO: Este trabalho teve como objetivo estudar a contribuição do sombreamento arbóreo para amenizar a radiação solar em instalações avícolas. Foram analisadas, por meio de simulação gráfica, instalações com dimensões utilizadas em produção avícola, com a cumeeira orientada na direção lesteoeste, bem como na norte-sul, situadas nas latitudes $0 ; 10 ; 20$ e $30^{\circ} \mathrm{S}$ e o sombreamento proporcionado por árvores de geometria de forma globosa. A eficiência do sombreamento foi analisada por meio de um Índice de Sombreamento $\left(I_{s g}\right)$, em função da localização temporal e espacial da instalação, que considera o efeito sombreador da árvore, interna e externamente. Para condições de verão, foi observado que, para o Norte e Nordeste do Brasil, o uso do sombreamento foi mais eficiente que para as regiões Sudeste e Sul, tanto para as instalações com orientação leste-oeste quanto para norte-sul, sendo verificado para o Nordeste $I_{s g}=25 \%$, para orientação leste-oeste, enquanto $I_{s g}=33 \%$ para orientação norte-sul. Quando analisada a orientação leste-oeste comparativamente à norte-sul, verificase que, em todas as latitudes, o sombreamento foi mais eficiente quando adotado para a orientação norte-sul, observando-se, por exemplo, para a região Sudeste $\mathrm{I}_{\mathrm{sg}}=21 \%$ (leste-oeste), enquanto $I_{\text {sg }}=32 \%$ (norte-sul).

PALAVRAS-CHAVE: sombreamento, avicultura, conforto ambiental.

\section{TREE SHADING AND ORIENTATION IN POULTRY HOUSES}

SUMMARY: This present paper deals with the contribution of tree shading to reduction radiation heat load in poultry houses. Typically dimensioned facilities, east-west and north-south-oriented, located at the southern latitudes of $0 ; 10 ; 20$ and 30 degrees were considered. Sheltering efficiency was expressed as an index in function of space and time. Such index $\left(\mathrm{I}_{\mathrm{sg}}\right)$ takes into account the shading effect of trees in and out the facility. Use of tree shading was more efficient in the north and northeast regions of Brazil, where the solar irradiation is higher than south and southeast regions. The east-west as well for the north-south orientations of the facilities the same was observed. An index of $\mathrm{I}_{\mathrm{sg}}$ of $25 \%$ was observed in the northeast region for east-west oriented facilities, while a value of $\mathrm{I}_{\mathrm{sg}}=33 \%$ was observed for the north-south orientation. For all the latitudes shading effects were more efficient in the north-south orientation. The Southeast index was $I_{\mathrm{sg}}=21 \%$ for the east-west and $I_{\mathrm{sg}}=32 \%$ for the north-south orientation.

KEYWORDS: shade, poultry, environmental comfort.

\footnotetext{
${ }^{1}$ Zootecnista, M.Sc., Professora Substituta, Departamento de Produção Animal, Instituto de Zootecnia, UFRRJ, Fone: (0XX21) 2682.1210, Ramal 406, e-mail: sula@ufrrj.br

${ }^{2}$ Professor Adjunto IV, Engenharia Agrícola, Departamento de Arquitetura e Urbanismo, IT/UFRRJ, e-mail: edrodrig@ufrrj.br Recebido pelo Conselho Editorial em: 3-9-2002

Aprovado pelo Conselho Editorial em: 2-12-2003
} 


\section{INTRODUÇÃO}

Segundo TINÔCO (1995), o ambiente ao qual as aves são submetidas, constitui um dos principais responsáveis pelo sucesso ou fracasso do empreendimento avícola, destacando-se os fatores térmicos, representados pela temperatura, pela umidade relativa e movimentação do ar, e pela radiação solar, os quais comprometem a manutenção da homeotermia. Ao incidir na construção e em seu entorno, a radiação solar converte-se em energia radiante na faixa do infravermelho, contribuindo para a elevação da temperatura do ambiente interno da edificação (STANGENHAUS, 1992). Projetar instalações adequadas leva a melhores condições de manejo e de conforto térmico, com reflexos em melhor sanidade e maior produtividade animal. $\mathrm{O}$ uso de arborização devidamente posicionada tornase uma barreira à radiação solar, contribuindo para diminuir o nível de carga térmica devido à radiação que incide nos animais e nos elementos construtivos da edificação. De acordo com GREY \& DENEKE (1978), citados por MILANO e DALCIN (2000), a contribuição das árvores como protetoras contra a radiação solar é significativa, já que as árvores e outros vegetais refletem, absorvem e transmitem radiação e, por meio da fotossíntese, também fixam energia, influenciando nas condições ambientais. Segundo FURTADO (1994), citado por BUENO (1998), a vegetação propicia resfriamento passivo de uma edificação por meio de: a) sombreamento lançado pela vegetação, que reduz a conversão da energia radiante em calor sensível, conseqüentemente, reduzindo as temperaturas da superfície dos objetos sombreados, e b) evaporação na superfície das folhas, resfriando essas com conseqüente diminuição da energia radiante para o entorno da vegetação.

Considerando que a orientação do eixo da instalação normalmente recomendada para o Hemisfério Sul, por razões de conforto térmico, é a leste-oeste, a qual, muitas vezes, por questões de topografia, se torna impossível de adotar, o presente trabalho teve como objetivo estudar a contribuição do sombreamento arbóreo para amenizar a incidência da radiação solar em instalações avícolas, quando a orientação adotada não for a ideal. Foram analisadas instalações com orientação leste-oeste comparativamente a instalações com orientação norte-sul.

\section{MATERIAL E MÉTODOS}

Foram analisadas, por meio de simulação gráfica, instalações com as dimensões tipicamente utilizadas na produção avícola, ou seja, $10 \mathrm{~m}$ de vão, $100 \mathrm{~m}$ de comprimento e $3 \mathrm{~m}$ de pé-direito, tendo o telhado de duas águas com inclinação de $20 \%$, beiral de $0,5 \mathrm{~m}$ e a cumeeira orientada na direção leste-oeste e norte-sul. Para o cálculo, utilizou-se de um trecho representativo da instalação de $30 \mathrm{~m}$ de comprimento, com árvores dispostas ao longo das laterais da instalação.

O estudo foi realizado considerando instalações situadas a $0 ; 10 ; 20$ e $30^{\circ}$ de latitude sul, que limitam as regiões produtoras avícolas de norte a sul do País. Para as latitudes citadas, foram determinados o azimute e a altura solar pelo programa RAD (CASTANHEIRA, 2001), bem como a intensidade de radiação solar direta, difusa e global pelo programa Casamo-Clim (CENTRE d' ENERGETIQUE, 1988).

A determinação do sombreamento propiciado pela árvore foi realizada por meio de simulação gráfica, considerando a arquitetura arbórea da Monguba (Pachira aquatica Aubl), espécie com potencial para atingir entre seis e oito anos de idade, $2,5 \mathrm{~m}$ de fuste de tronco e copa globosa com $4 \mathrm{~m}$ de diâmetro, sendo esses os valores utilizados para a obtenção dos dados. Consideraram-se árvores situadas a 2,5;3,0; 3,5 e 4,0 $\mathrm{m}$ das laterais da instalação, com $5 \mathrm{~m}$ de espaçamento entre as árvores. A sombra da copa da árvore (considerada uma esfera) sobre o plano horizontal é uma elipse que foi determinada para as $8 ; 9 ; 10 ; 11$ e $12 \mathrm{~h}$ pelo método das projeções mongeanas da geometria descritiva, utilizando como ferramenta computacional o Auto $C A D$. Foi elaborado um índice de sombreamento em função da localização temporal e espacial da instalação, que considera o efeito sombreador da árvore interna e externamente à instalação. $\mathrm{O}$ índice de sombreamento é uma ferramenta de análise, de 
modo que se possa expressar em um só número o efeito, tanto do sombreamento externo quanto do interno, bem como da época do ano e da hora do dia, além de considerar o efeito reflexivo (albedo) do entorno da edificação. O índice é apresentado nas eqs. (1), (2) e (3).

$$
\begin{aligned}
& \mathrm{I}_{\mathrm{sg}}=\mathrm{I}_{\mathrm{si}}+\alpha \mathrm{I}_{\mathrm{se}} \\
& \mathrm{I}_{\mathrm{si}}=\frac{100 \mathrm{~A}_{\mathrm{ti}}{ }^{-1}\left[\mathrm{E}_{8} \mathrm{~A}_{\mathrm{si}(8)}+\mathrm{E}_{9} \mathrm{~A}_{\mathrm{si}(9)}+\mathrm{E}_{10} \mathrm{~A}_{\mathrm{si}(10)}+\mathrm{E}_{11} \mathrm{~A}_{\mathrm{si}(11)}+\mathrm{E}_{12} \mathrm{~A}_{\mathrm{si}(12)}\right]}{\mathrm{E}_{(8)}+\mathrm{E}_{(9)}+\mathrm{E}_{(10)}+\mathrm{E}_{(11)}+\mathrm{E}_{(12)}} \\
& \mathrm{I}_{\mathrm{se}}=\frac{100 \mathrm{~A}_{\mathrm{te}}{ }^{-1}\left[\mathrm{E}_{8} \mathrm{~A}_{\mathrm{se}(8)}+\mathrm{E}_{9} \mathrm{~A}_{\mathrm{se}(9)}+\mathrm{E}_{10} \mathrm{~A}_{\mathrm{se}(10)}+\mathrm{E}_{11} \mathrm{~A}_{\mathrm{se}(11)}+\mathrm{E}_{12} \mathrm{~A}_{\mathrm{se}(12)}\right]}{\mathrm{E}_{(8)}+\mathrm{E}_{(9)}+\mathrm{E}_{(10)}+\mathrm{E}_{(11)}+\mathrm{E}_{(12)}}
\end{aligned}
$$

em que,

$\mathrm{I}_{\mathrm{sg}}, \mathrm{I}_{\mathrm{si}}, \mathrm{I}_{\mathrm{se}}$ - índice de sombreamento global, interno e externo, respectivamente;

$\mathrm{A}_{\mathrm{si}}, \mathrm{A}_{\mathrm{se}}, \mathrm{A}_{\mathrm{ti}}, \mathrm{A}_{\mathrm{te}}$ - área sombreada interna, externa, total interna $\left(300 \mathrm{~m}^{2}=10 \mathrm{x} 30\right)$ e total externa (área considerada como de influência do sombreamento);

$\mathrm{E}_{(\mathrm{h})}$ - radiação solar global horária (fator ponderador da média), e

$\alpha$ - albedo do solo nu $(0,30)$.

\section{RESULTADOS E DISCUSSÃO}

Na Figura $1(\mathrm{a}, \mathrm{b})$, é mostrado o sombreamento propiciado pelas árvores, em um trecho de $30 \mathrm{~m}$ da instalação, considerando-se com orientações leste-oeste e norte-sul. O distanciamento da árvore ao galpão utilizado foi de $2,5 \mathrm{~m}$, o qual se mostrou mais adequado por proporcionar maior quantidade de sombra no interior da instalação. Ao observar essa figura, verifica-se que o sombreamento propiciado pelas árvores é mais efetivo quando a instalação está com a orientação norte-sul, com área de sombra de $46 \mathrm{~m}^{2}$, sendo para a orientação leste-oeste nula a área sombreada interna.

Observando-se a Tabela 1, verifica-se, por exemplo, para a latitude $30^{\circ} \mathrm{S}$, no verão, que o índice de sombreamento varia de $21 \%$ para a orientação leste-oeste, a $31 \%$ para a orientação norte-sul. $\mathrm{O}$ mesmo comportamento foi observado para as demais latitudes e horários estudados.

Observando-se a Figura 2, verifica-se que, em condições de verão, o uso do sombreamento foi mais eficiente nas baixas latitudes do que nas latitudes maiores, tanto para instalações com orientação leste-oeste quanto para instalações norte-sul, sendo verificado para o Nordeste $\mathrm{I}_{\mathrm{sg}}=25 \%$, para orientações leste-oeste, enquanto $\mathrm{I}_{\mathrm{sg}}=33 \%$ para orientação norte-sul. Quando analisada a orientação leste-oeste em comparação à norte-sul, verifica-se que, em todas as latitudes, o sombreamento foi mais eficiente quando adotado para a orientação norte-sul, observando-se, por exemplo, para uma região a $20^{\circ}$ de latitude, $\mathrm{I}_{\mathrm{sg}}=21 \%$ (leste-oeste), enquanto $\mathrm{I}_{\mathrm{sg}}=32 \%$ (norte-sul). 

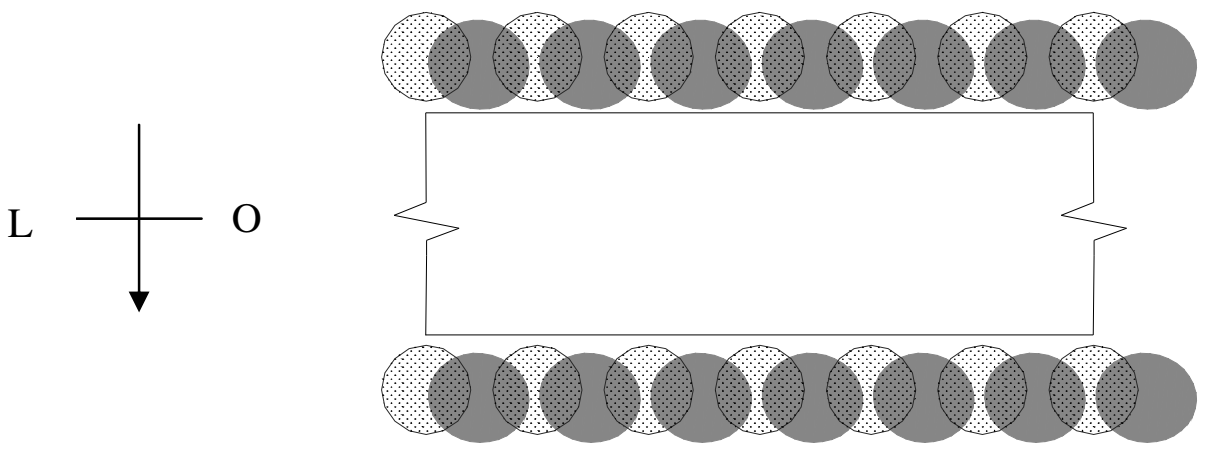

(a)

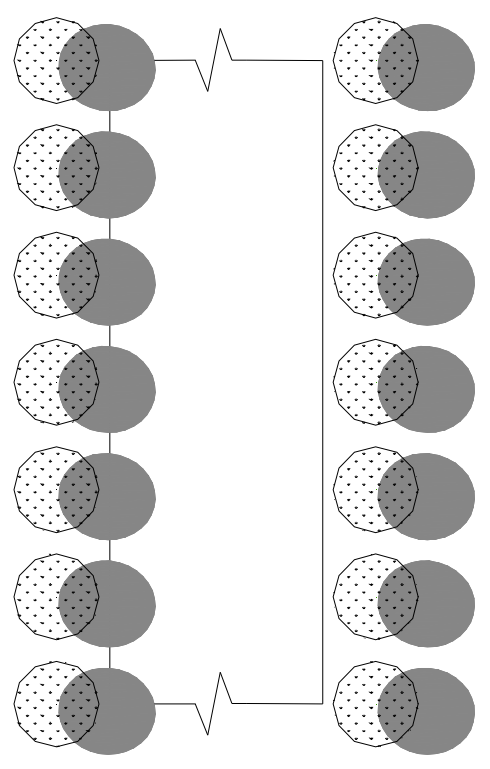

(b)

FIGURA 1. Sombreamento para instalações situadas a $20^{\circ} \mathrm{S}$, para afastamento de árvores de $2,5 \mathrm{~m}$, às 10 h, em condição de verão, para instalações com orientação leste-oeste (a) e norte-sul (b).

TABELA 1. Índice de sombreamento global $\left(\mathrm{I}_{\mathrm{sg}}\right)$ para as latitudes 0; 10; 20 e $30^{\circ} \mathrm{S}$, para galpões com orientação leste-oeste e norte-sul, afastamento de árvores ao galpão de $2,5 \mathrm{~m}$, em condições de verão, inverno e meia-estação.

\begin{tabular}{|c|c|c|c|c|}
\hline \multicolumn{5}{|c|}{ Orientação Leste-Oeste } \\
\hline Estação & Latitude $0^{\circ}$ & Latitude $10^{\circ}$ & Latitude $20^{\circ}$ & Latitude $30^{\circ}$ \\
\hline & \multicolumn{4}{|c|}{$\mathrm{I}_{\mathrm{sg}}(\%)$} \\
\hline Verão & 33 & 25 & 21 & 21 \\
\hline Inverno & 36 & 47 & 63 & 76 \\
\hline Meia-estação & 20 & 22 & 20 & 38 \\
\hline \multicolumn{5}{|c|}{ Orientação Norte-Sul } \\
\hline Estação & Latitude $0^{\circ}$ & Latitude $10^{\circ}$ & Latitude $20^{\circ}$ & Latitude $30^{\circ}$ \\
\hline & \multicolumn{4}{|c|}{$\mathrm{I}_{\mathrm{sg}}(\%)$} \\
\hline Verão & 38 & 33 & 32 & 31 \\
\hline Inverno & 35 & 41 & 48 & 55 \\
\hline Meia-estação & 34 & 34 & 36 & 40 \\
\hline
\end{tabular}




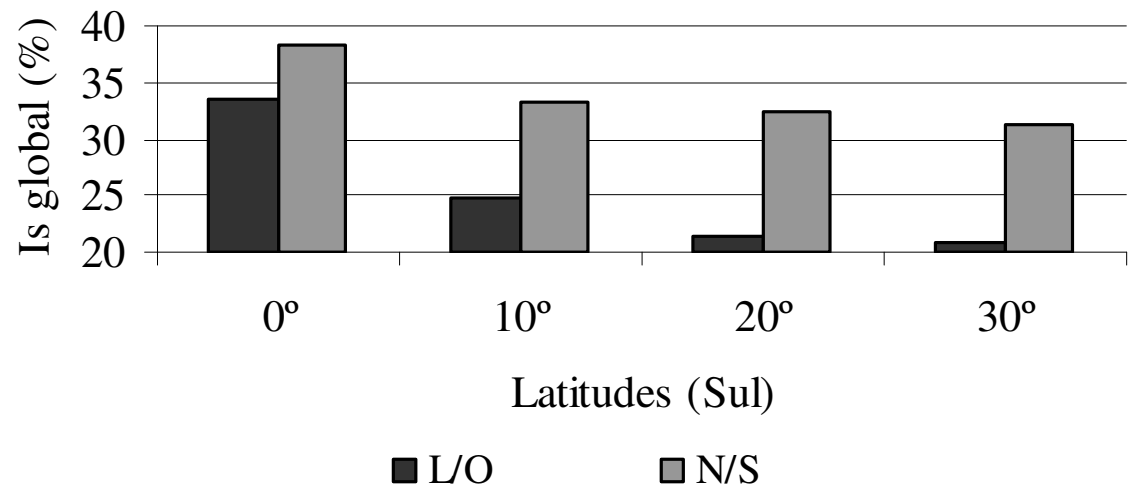

FIGURA 2. Índice de sombreamento global para instalações com orientação leste-oeste e norte-sul em função da latitude para a condição de verão, para afastamento de árvores de 2,5 m.

\section{CONCLUSÕES}

A análise do efeito do sombreamento propiciado em determinada latitude pela espécie arbórea, por meio do índice de sombreamento global, indicou a possibilidade de obstrução da radiação solar incidente sobre a edificação, tanto para instalações com orientação leste-oeste, quanto para orientação norte-sul, sendo, no entanto, mais eficiente quando o sombreamento é aplicado em instalações com orientação norte-sul, constituindo-se num modo de amenizar os problemas ambientais gerados pelo uso da orientação incorreta. O sombreamento mostrou-se mais eficiente quando adotado para a região de baixa latitude, constituindo-se numa solução adequada para amenizar as condições adversas de alta intensidade de radiação solar observadas nas regiões Norte e Nordeste do Brasil.

\section{REFERÊNCIAS BIBLIOGRÁFICAS}

BUENO, C.L. Estudo da atenuação da radiação solar incidente por diferentes indivíduos arbóreos. 1998. 178 f. Tese (Doutorado em Engenharia Civil) - Faculdade de Engenharia Civil, Universidade Estadual de Campinas, Campinas, 1998.

CASTANHEIRA, R.G. Radiação solar incidente em planos inclinados, fachadas e telhados no Rio de Janeiro. 2001. 197 f. Dissertação (Mestrado em Arquitetura e Urbanismo) - Faculdade de Arquitetura e Urbanismo, Universidade Federal do Rio de Janeiro, Rio de Janeiro, 2001.

CENTRE d' ENERGETIQUE-CASAMO-CLIM. Manuel d'utilization 1989 et cahier scientifique version 1988. IBM PC et Compatibles. École de Mines de Paris. Paris, 1988.

MILANO, M.; DALCIN, E. Arborização de vias públicas. Rio de Janeiro: Light, 2000. 226 p.

STANGENHAUS, C.R. Paredes, conforto higrotérmico, edificações, ponderações e propostas para clima tropical úmido em situação de verão. 1992. 198 f. Dissertação (Mestrado em Arquitetura e Urbanismo) - Faculdade de Arquitetura e Urbanismo, Universidade Federal do Rio de Janeiro, Rio de Janeiro, 1992.

TINÔCO, I. F. F. Estresse calórico: meios artificiais de condicionamento. In: SIMPÓSIO INTERNACIONAL DE AMBIÊNCIA E INSTALAÇÃO NA AVICULTURA INDUSTRIAL, 1995, Campinas. Anais... p.99-108. 